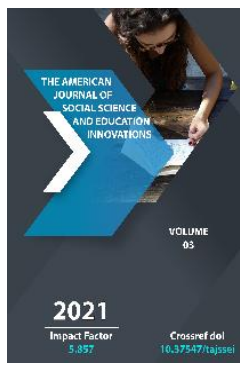

\title{
Emergency Conversation Expertise In Participate Freedom With Civilian Society
}

\author{
Janifer Lopez \\ Department Of Communication, Tampere University , Finland
}

Journal Website:

http://usajournalshub.c om/index,php/tajssei

Copyright: Original content from this work may be used under the terms of the creative commons attributes 4.0 licence.

\section{ABSTRACT}

The point of this article is to investigate relational correspondence capability required by crisis correspondence and the board specialists when co-working with resident gatherings accordingly to emergencies. Also, the object is to see how reaction associations can advance develop this emergency correspondence ability thus add to the working of reaction networks. The research task is drawn nearer subjectively by evoking emergency correspondence and management experts impression of the relational correspondence skill reaction organizations needs when co-working with resident gatherings. The information were assembled through a worldwide online questionnaire utilizing a technique alluded to as "topical composition" and comprise of composed reactions to open-finished inquiries on what establishes the center of emergency correspondence fitness and what aspects of it need more consideration. The exploration discoveries demonstrate that co-delivering wellbeing with citizen society requests emergency correspondence ability identified with message creation, message reception, and connection among specialists and resident gatherings. Furthermore, the discoveries explain what zones of crisis correspondence skill should be additionally evolved to work with coactivity between experts and resident gatherings. Nonetheless, the creators propose that emergency correspondence competence should not be seen exclusively as an attribute of individual emergency communicators however drew closer as a networked and co-made space of fitness

\section{KEYWORDS}

Community approach; emergency correspondence; emergency correspondence competence interpersonal correspondence skill 


\section{INTRODUCTION}

Successful emergency the executives requires co-activity between different response organizations as well as with resident gatherings to co-produce security and adjust to changing situations. This article analyzes a local area way to deal with emergency the executives known additionally as a entire local area approach where resident gatherings are not seen simply as target bunches but instead as dynamic co-entertainers because of crises. The significance of this co-activity calls for the development of specialists' fitness in relational correspondence and social interaction. Crises can be described as explicit, undermining conditions that take individuals by surprise ,create undeniable degrees of vulnerability, and request quick dynamic . In this paper, we center on emergencies and cataclysmic events as opposed to notoriety emergencies. Since each emergency circumstance is different and advances over the long run, getting ready for emergencies is testing . Besides, since emergency is a interaction of change where the old framework can at this point don't be kept up , crisis situations require learning and evolving. Also, the capacity to adapt to emergencies while co-working with different entertainers requires that emergency correspondence and the executives specialists have expertise in relational correspondence and social connection .

\section{METHOD}

In this article, emergency correspondence skill was inspected by zeroing in on specialists' own experiences and comprehension of the theme. Gathering composed reactions to open- finished questions gave the respondents the chance to ponder their encounters. Notwithstanding, the strategy may also have its disadvantages. It is regularly expressed that depicting the ability one uses and needs at work may not be a simple assignment . In this manner, the respondents' capacity to recall and describe their encounters verbally may have affected the exploration discoveries. Moreover,the respondents' inspiration to take an interest in the investigation and the time.

\section{DISCUSSION}

Crisis correspondence and the board specialists experience a wide assortment of interpersonal conversation and social cooperation circumstances over the span of their work. By the by, few studies have inspected their work from the point of view of relational correspondence competence. Given that the unpredictable idea of flow emergencies requires emergency correspondence capability and a local area way to deal with emergency the board requires the improvement of specialists' skill in interpersonal correspondence and social collaboration, this absence of exploration is astounding and unfortunate. This article added to past research on emergency correspondence and the executives by explaining the areas of emergency correspondence ability required by emergency correspondence and the executives experts when co-working with resident gatherings because of crises. Likewise, the exploration findings indicated what spaces of specialists' emergency correspondence ability should be 
additionally evolved in order to work with coactivity among specialists and resident gatherings.

\section{CONCLUSION}

This examination added to past research on emergency correspondence and the executives by applying the idea of relational correspondence capability to an emergency correspondence and management setting and gave bits of knowledge into the necessities of emergency correspondence and management specialists' relational correspondence ability required in co-creating security with civilian gatherings. The examination discoveries are required in creating formal correspondence education and proficient preparing of emergency correspondence and the board specialists and in supporting their casual learning at work. It was proposed that this skill region, alluded to as crisis conversation fitness, ought to be viewed as co-made in the connections among crisis conversation and the executives specialists and resident gatherings just as between different entertainers forming the reaction organization. Subsequently, the investigation added to past research on emergency correspondence and management by building up another idea that offers a novel hypothetical way to deal with understand and build up the working of reaction organizations. Besides, it underlined a requirement for broad ening the present individual-situated examination custom of relational correspondence skill and laid accentuation on concocting inventive approaches to decide shared improvement needs and to develop a co-made emergency correspondence capability on a social level. It was contended that a shift from focusing on building up specialists emergency correspondence to expounding on dialogical emergency interaction as such is expected to reinforce emergency the board. Furthermore, the investigation gave experiences into the orizing a multi-entertainer network emergency correspondence fitness.

\section{REFRENCES}

1. Federal Emergency Management Agency, United States Department of Homeland Security. A Whole Community Approach to Emergency Management: Principles, Themes, and Pathways for Action.

2. Wadra r. a. Umer, Tidgthy, L.s pathry, and angilo M. Seeger .Effective Crisis Conversation: Moving from Crisis to Opportunity. Thousand Oaks: Sage, 2006.

3. Bumra j.filmajer, and b.t.hada. Emergency communicators in change: From plans to improvisations. In The Handbook of Crisis Conversation .

4. Fleming s. u.v.gurtae Hazard Conversation in a High Reliability Organization: APHIS PPQ's Inclusion of Risk in Decision Making..

5. B.lara, m. johnberg, and Wilson g. skull f. . Relational abilities. In The Sage Handbook of Interpersonal Conversation.

6. H.lidon dilene, and krant k. wilson, eds .Handbook of Conversation and Social Interaction Skills. . 